\title{
Transcriptional activity of PIF and Pong-like Class II transposable elements in Triticeae
}

\author{
Dragomira N. Markova ${ }^{1,2^{*}}$ and Roberta J. Mason-Gamer ${ }^{1}$
}

\begin{abstract}
Background: Transposable elements are major contributors to genome size and variability, accounting for approximately $70-80 \%$ of the maize, barley, and wheat genomes. PIF and Pong-like elements belong to two closely-related element families within the PIF/Harbinger superfamily of Class II (DNA) transposons. Both elements contain two open reading frames; one encodes a transposase (ORF2) that catalyzes transposition of the functional elements and their related non-autonomous elements, while the function of the second is still debated. In this work, we surveyed for PIF- and Pong-related transcriptional activity in 13 diploid Triticeae species, all of which have been previously shown to harbor extensive within-genome diversity of both groups of elements.

Results: The results revealed that PIF elements have considerable transcriptional activity in Triticeae, suggesting that they can escape the initial levels of plant cell control and are regulated at the post-transcriptional level.

Phylogenetic analysis of 156 PIF CDNA transposase fragments along with 240 genomic partial transposase sequences showed that most, if not all, PIF clades are transcriptionally competent, and that multiple transposases coexisting within a single genome have the potential to act simultaneously. In contrast, we did not detect any transcriptional activity of Pong elements in any sample.

Conclusions: The lack of Pong element transcription shows that even closely related transposon families can exhibit wide variation in their transposase transcriptional activity within the same genome.
\end{abstract}

Keywords: PIF-like, Pong-like, Transposable elements, DNA transposon, Class II, Transcription, Phylogeny, Triticeae

\section{Background}

Triticeae is a pooid tribe with approximately 30 genera and 300-400 species [1], including wheat, barley, and rye. The tribe's economic importance has made it the focus of many evolutionary and genetic studies over the last few decades. The Triticeae genome is large and complex, with approximately $70-80 \%$ composed of transposable elements (TEs) [2-7].

Eukaryotic TEs have been divided into two main groups based on their structure and transposition mechanism. Class I TEs (retrotransposons) transpose by reverse transcription of an RNA intermediate, while Class II TEs (DNA elements) transpose via a double-stranded DNA intermediate through a "cut and paste" mechanism whereby the element is excised and reinserted elsewhere

\footnotetext{
*Correspondence: markova@ucdavis.edu

${ }^{1}$ Department of Biological Sciences, University of Illinois at Chicago, M/C 067 840 West Taylor Street, Chicago, IL 60607, USA

${ }^{2}$ Present address: Department of Plant Sciences (mail stop 3), 151

Asmundson Hall, University of California, Davis, CA 95616, USA
}

in the host genome. These usually have terminal inverted repeats (TIRs) whose size and sequence are characteristic of the family or superfamily to which the element belongs. Autonomous Class II elements encode all functional products required for transposition, including a transposase gene (TPase) that catalyzes DNA cleavage and transposition. Non-autonomous elements are usually deletion derivatives of autonomous elements that only retain the terminal sequences necessary for recognition and activation by the transposition machinery of autonomous elements $[8,9]$. All TE superfamilies contain both autonomous and non-autonomous elements [10].

Transposable elements are major contributors to genome size and variability, and gene evolution [11-16]. Their ability to move and amplify within a genome results in mutational activity that can alter gene structure and function $[17,18]$ through loss of genes [12, 14, 15], changes in expression levels [19], or evolution of new functions [20-22]. Once integrated in the genome, some TEs accumulate mutations and become transcriptionally 
and/or transpositionally inactive [23-26]. A fine balance between transcription, transposition, and host survival should be reached, and the host tightly controls the activity of TEs [27]. However, despite mutation and cell control, some TEs remain transcriptionally and transpositionally active [28-34].

This work is focused on the transcriptional activity of a superfamily of Class II elements called PIF/Harbinger in the genomes of 13 diploid species from the wheat tribe, Triticeae. The PIF/Harbinger elements form a widespread superfamily of DNA transposons, which consists of PIF and Pong-like elements. PIF and Pong-like elements were first discovered in the maize [34] and rice [30] genomes, respectively, and they have since been detected in the genomes of many flowering plants, animals, and fungi [28, 35-38].

Most PIF and Pong elements are approximately 4$6 \mathrm{~kb}$ long [28, 30, 35] and contain two open reading frames (ORFs), one encoding a transposase (ORF2), and one whose function is still not known (ORF1) (Fig. 1a), though it is thought to be involved in DNA binding activity and protein-protein interactions [39-42]. The transposase contains a "DDE" motif, a signature consisting of an amino acid triad identified in the transposases of most DNA transposon superfamilies (Fig. 1a) [43, 44]. The "DDE" motif consists of two aspartic acid (D) residues and glutamic acid (E) residue interspersed within a relatively well conserved domain of amino acids, which has been used to establish the evolutionary relationships among PIF and Pong elements [35, 37, 38, 42, 45, 46]. In some PIF elements the transposase gene is interrupted by between one to three insertions characterized as introns [36, 38, 47].

We have demonstrated that PIF and Pong elements in the genomes of diploid Triticeae species are abundant and highly variable, and represent multiple diverse lineages within genomes that appear to predate the origin of the tribe itself $[45,46]$. To determine whether they are transcriptionally active, we screened 15 diploid individuals from 13 species for the presence of PIF and Ponglike transcripts, and we performed phylogenetic analyses of both genomic DNA and cDNA copies to establish whether the detected transcripts are produced by several or only few transposase lineages. We found that PIF-like transposases are actively transcribed in Triticeae and that most, if not all, transposase lineages that we previously identified are transcriptionally competent [45]. In contrast to our evidence of PIF transcription, we did not detect any transcriptional activity of Pong elements in any sample.

\section{Methods}

\section{Plant material}

Fifteen accessions of 13 species representing 11 Triticeae genera were used to survey for the presence of PIF and Pong-like related transcripts (Table 1). To avoid the

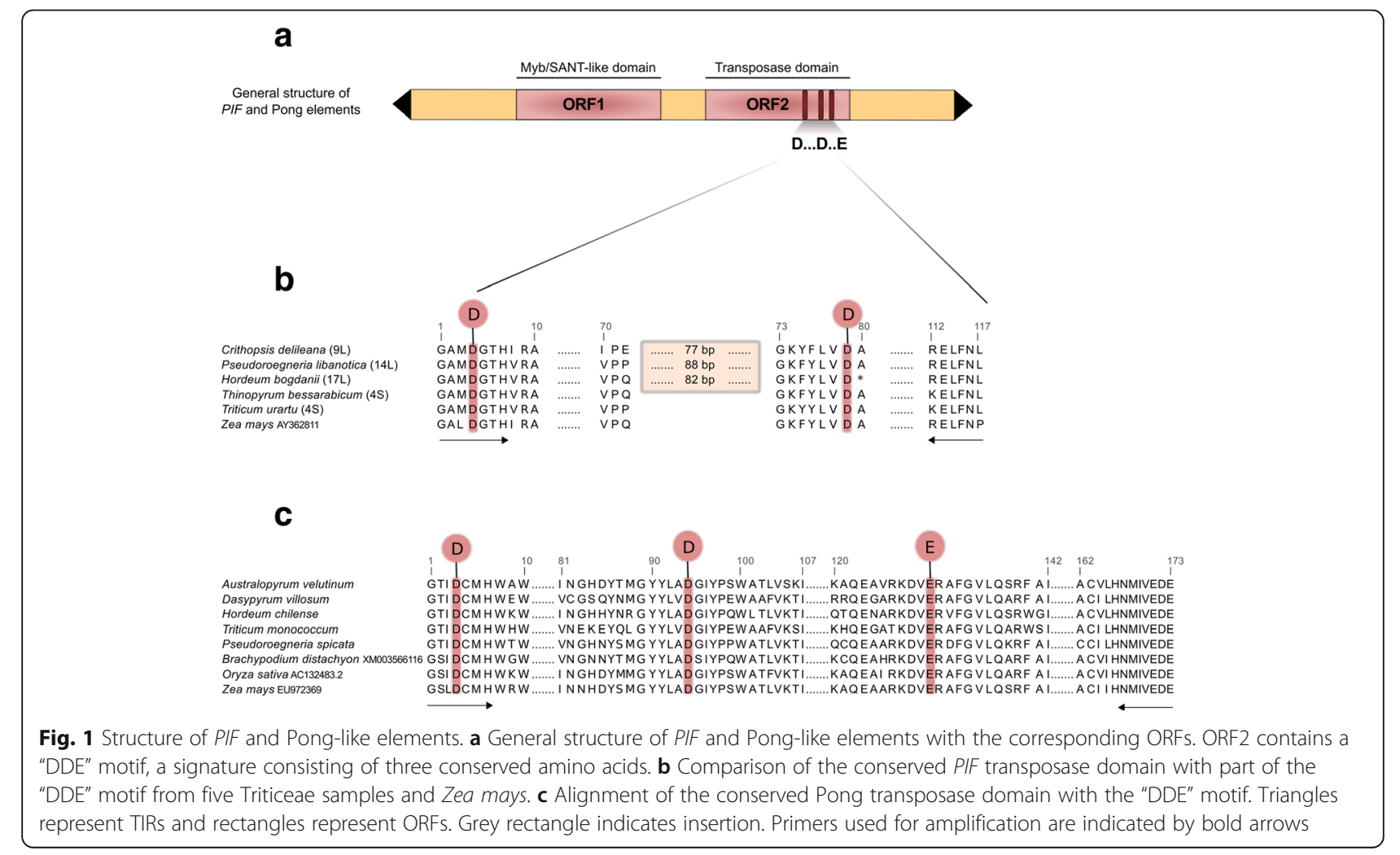


Table 1 List of Triticeae taxa included in PIF transcriptional analyses. Samples are represented with their names and collection numbers

\begin{tabular}{|c|c|c|}
\hline & genomic $P / F^{a}$ & CDNA PIF \\
\hline Species name & Sample source and reference number & Sample source and reference number \\
\hline Aegilops comosa Sibth. \& Smith & USDA/G602 & USDA/PI 542175 \\
\hline Agropyron cristatum (L.) Gaertn. & USDA/PI 279802 & USDA/PI 439925 \\
\hline Australopyrum velutinum (Nees) B.K.Simon & USDA/D 2873-2878 & \\
\hline Crithopsis delileana (Schult.) Roshev. & USDA/H 5562 & USDA/H 5562 \\
\hline Dasypyrum villosum (L.) P.Candargy & USDA/D 2990 & \\
\hline Eremopyrum bonaepartis (Spreng.) Nevski & USDA/PI 227344 & USDA/PI 219970 \\
\hline Henrardia persica (Boiss.) C.E.Hubb & USDA/H 5556 & \\
\hline Heteranthelium piliferum (Banks \& Sol.) Hochst. & USDA/PI 402352 & \\
\hline Hordeum bogdanii Wilensky (1) & & USDA/PI 531760 \\
\hline Hordeum bogdanii Wilensky (2) & USDA/PI 531762 & USDA/PI 531762 \\
\hline Hordeum chilense Roem. \& Schult. & USDA/PI 531781 & \\
\hline Peridictyon sanctum (Janka) Seberg, Fred., \& Baden & USDA/KJ 248 & \\
\hline Psathyrostachys fragilis (Boiss.) Nevski & USDA/PI 343192 & \\
\hline Psathyrostachys juncea (Fisch.) Nevski & USDA/PI 206684 & USDA/PI 272136 \\
\hline Pseudoroegneria libanotica (Hack.) D.R.Dewey & USDA/PI 228391 & USDA/PI 228389 \\
\hline Pseudoroegneria spicata (Pursh) Á.Löve & USDA/D 2844 & USDA/PI 236672 \\
\hline Pseudoroegneria tauri (Boiss. \& Balansa) Á.Löve & USDA/PI 401319 & \\
\hline Secale montanum Guss. & USDA/T 36554 & USDA/T 36554 \\
\hline Taeniatherum caput-medusae (L.) Nevski (1) & USDA/PI 208075 & USDA/PI 222048 \\
\hline Taeniatherum caput-medusae (L.) Nevski (2) & USDA/PI 283240 & USDA/PI 220591 \\
\hline Thinopyrum bessarabicum (Săvul. \& Rayss) Á.Löve & USDA/PI 531711 & USDA/PI 531711 \\
\hline Triticum monococcum L. & USDA/PI 221413 & USDA/PI 10474 \\
\hline Triticum urartu Tumanian ex Gandilyan & Morrison s.n. & Morrison s.n. \\
\hline
\end{tabular}

${ }^{\mathrm{a}}$ Genomic PIF sequences are from [45]

potentially confounding phylogenetic effects of autoand allopolyploidy, only diploid taxa were chosen for this study. Seeds were obtained from the USDA and have associated chromosome counts. All plants were grown at the University of Illinois at Chicago greenhouse under common conditions. The PIF cDNA sequences were analyzed alone (Fig. 2) and in combination with two hundred and forty genomic PIF ORF2 sequences from 22 diploid Triticeae samples [[45]; Table 1] (Fig. 3).

\section{DNA, RNA extractions and cDNA synthesis}

The DNA was extracted for previous phylogenetic studies from fresh or dried leaf material, using a CTABbased method [48]. RNA was extracted from fresh leaf material harvested from reproductively mature plants (Table 1). Plant tissue was snap-frozen in liquid nitrogen and total RNA was extracted using a commercial extraction kit (Promega), following the manufacturer's instructions. Crude total RNA preparations were treated with TURBO DNA-free ${ }^{\text {Tx }}$ (Ambion) to remove residual DNA. RNA quality was inferred by running $5 \mu \mathrm{l}$ on an agarose gel, and RNA concentrations were estimated using a NanoDrop Spectrophotometer (Thermo Fisher Scientific Inc., MA, USA). Prior to cDNA synthesis, the presence/ absence of genomic DNA contamination was tested for all RNA preparations using PCR reactions with PIF and Pong primers known to work on genomic DNA, and an RT- control supplied with the cDNA synthesis kit. cDNA was generated from DNA-free total RNA using the Protoscript RT-PCR kit (NEB) using $2 \mu \mathrm{l}$ of random and oligo-dT primers and following the manufacturer's protocol. The cDNAs were used as templates in amplification reactions as described below.

\section{Amplification of the PIF ORF2 conserved domain}

Triticeae-specific degenerate primers (cPIF-for: GGAGC HWTNGATGGYACWCAC, cPIF-rev: AAGGTTGAAY AGCTCCYT) targeting a conserved portion of the PIF transposase were used for all PCR amplifications (Fig. 1b). These primers are anchored in two highly conserved amino acid residue motifs (GAMDGTH and RELFNL respectively) of the transposase gene, surrounding the "DD" 


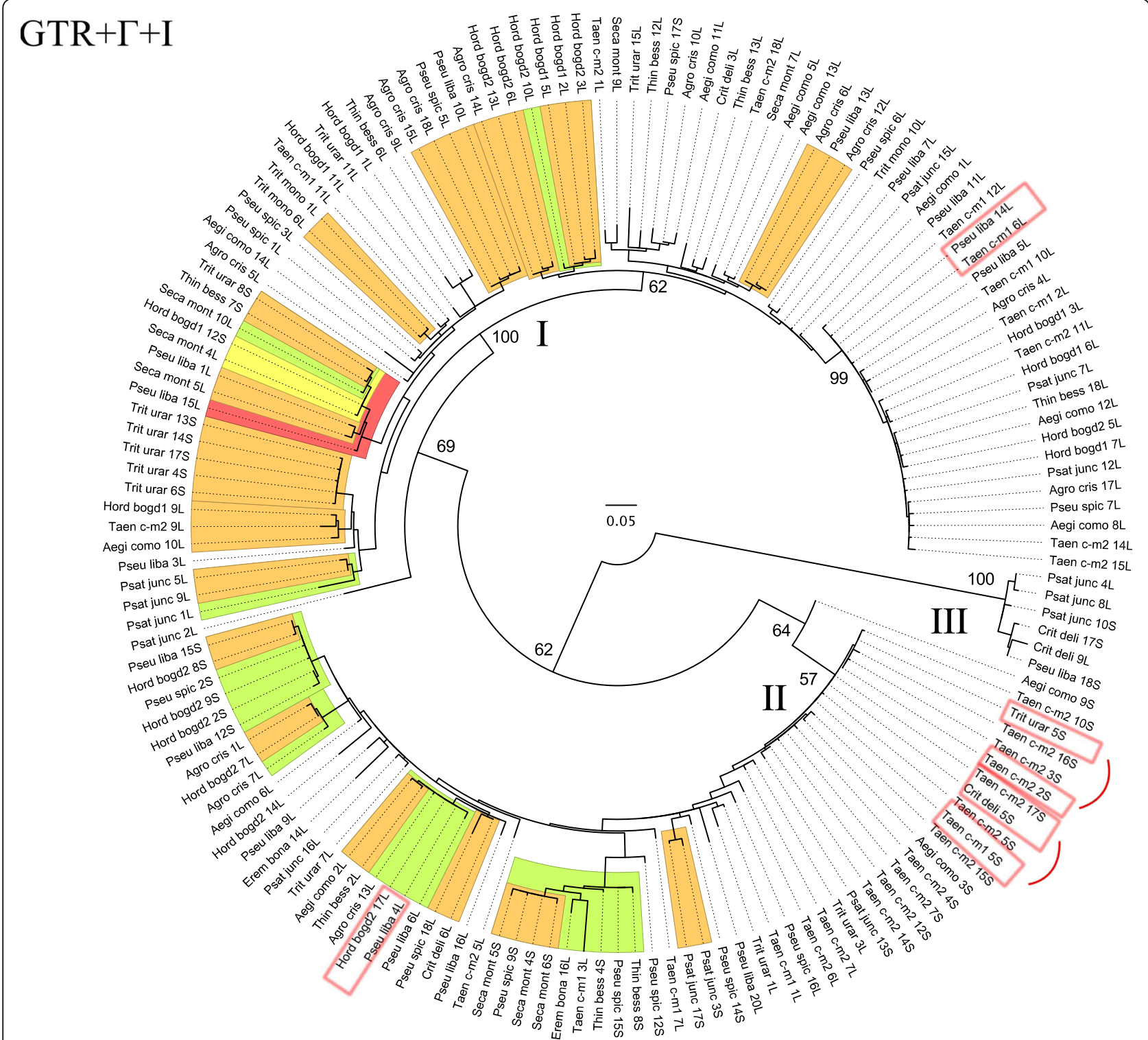

Fig. 2 100-replicate ML bootstrap analysis of 156 PIF-like CDNA transposase sequences from Triticeae under the GTR+ $\lceil+\mid$ model of evolution. Colored clades represent clades with bootstrap support above $80 \%$. Bootstrap values of main clades are displayed with numbers. Red rectangles indicate identical sequences from distinct genera. Taxon labels combine the first four letters of the genus and species names. Numbers following taxon names distinguish cloned sequences from within individuals and are consistent among Figs. 2 and 3. S designates short sequences without the intron; $L$ designates long sequences with the intron

portion of the "DDE" motif. The predicted TPases encoded by plant PIF transposons vary in length from 392 to 432 amino acids [42]; the amplified portion represents between 120 and 147 amino acids. The position of the "DD" transposase fragment was predicted by comparison of a reduced set of aligned Triticeae sequences to the corresponding portion of the "DDE" motif from a Zea mays PIF element (AY362811; Fig. 1b). All amplifications were carried out in a $10 \mu \mathrm{l}$ reactions containing $50 \mathrm{ng}$ of cDNA, 10× PCR buffer, $0.1 \mathrm{mmol} / \mathrm{L}$ of each primer, 0.5 units of Taq polymerase (Sigma), $0.2 \mathrm{mmol} / \mathrm{L}$ of each $\mathrm{dNTP}$, and
$1.5 \mathrm{mmol} / \mathrm{L} \mathrm{MgCl}_{2}$. The PCR amplification conditions were: 5 min of DNA denaturation at $95{ }^{\circ} \mathrm{C}$, followed by 35 cycles of $30 \mathrm{~s}$ at $95{ }^{\circ} \mathrm{C}, 45 \mathrm{~s}$ at $57^{\circ} \mathrm{C}$ and $60 \mathrm{~s}$ at $72{ }^{\circ} \mathrm{C}$ for each cycle. The last cycle was followed by a $10 \mathrm{~min}$ final extension at $72{ }^{\circ} \mathrm{C}$.

\section{Amplification of the Pong ORF2 conserved domain}

Degenerate primers (Pong-for: GGCWCCATYGAYTGTATGCAC, Pong-rev: YTCGTCYTCVACYATCATRTTGTG; [37]) were used for cDNA amplification of approximately one-third or 520 bp of conserved 


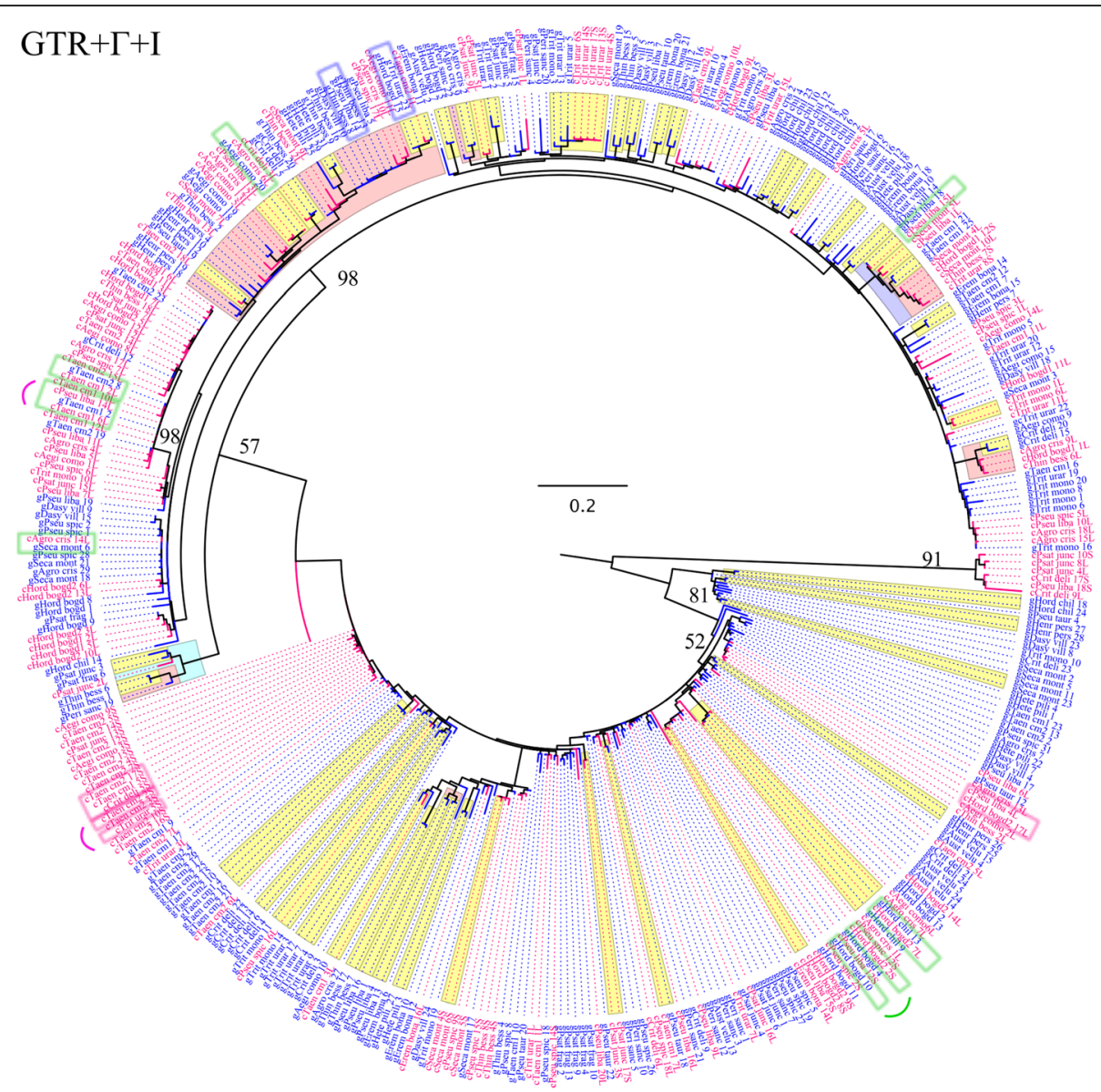

Fig. 3 100-replicate ML bootstrap analysis of 156 PIF-like cDNA transposase sequences (c-pink) and 240 genomic (g-blue) PIF transposase fragments under the $\mathrm{GTR}+\Gamma+I$ model of evolution. Colored clades represent clades with bootstrap support above $80 \%$. Bootstrap values of main clades are displayed with numbers. Pink rectangles indicate identical cDNA sequences; blue rectangles indicate identical genomic DNA sequences; green rectangles indicate identical cDNA and genomic DNA sequences. Taxon labels combine the first four letters of the genus and species names. Numbers following names distinguish cloned sequences from within individuals and are consistent among Figs. 2 and 3. S designates short sequences without the intron; $L$ designates long sequences with the retained intron

region of the Pong transposase domain, including the "DDE" motif. These primers are anchored in two highly conserved amino acid residue blocks (GTIDCMH and NMIVEDE) of the transposase gene (Fig. 1c) and were previously shown to work on genomic DNA [37, 46]. All amplifications were carried out as described in [46].

\section{Cloning, sequencing and sequence alignment}

PCR products were cloned prior to sequencing, and multiple clones from each species were sequenced to evaluate intra-individual transposase diversity. Three PCR reactions were run for each cloning reaction to counter the potential effects of PCR drift [49]. PCR products from replicated reactions were isolated on $1 \%$ agarose gels, combined and purified on columns (Qiagen). Cleaned products were cloned into pGEM-T Easy vectors (Promega) and transformed into E.coli JM109 competent cells (Promega) according to the manufacturer's instructions, except that all reactions were halved. Positive (white) colonies containing the insert were PCR amplified as described above. The resulting fragments were cleaned with $0.2 \mu \mathrm{l}$ exonuclease and $0.4 \mu \mathrm{l}$ shrimp alkaline phosphatase, and sequenced in both directions with the PCR primers. Sequencing was performed on an ABI 377 automated sequencer (Applied Biosystems). The nucleotide and inferred amino acid sequences of PIF-like transposases were aligned using CLUSTALW [50] with default parameters, and then manually adjusted in MacClade 4.08 (Maddison and Maddison). All alignments are available upon request.

\section{Phylogenetic analysis}

Phylogenies were estimated using maximum parsimony (MP) and maximum likelihood (ML). Parsimony analyses and pairwise sequence distances were estimated with PAUP* v.4.0b10 [51]. The parsimony bootstrap 
method, with 1000 replicates with heuristic search, was used to estimate the robustness of the clades [52] (tree not shown). For the ML analysis, the appropriate model of sequence evolution was determined by jModelTest [5355] and the corrected Akaike information criterion [56]. The selected models of evolution were implemented in the Mac OS X version of GARLI v.0.95 [57] for analysis. Following the recommendations of the author, multiple (50) analyses with random starting tree topologies were performed for each data set. Runs were set for an unlimited number of generations, and automatic termination following 10,000 generations without a significant change in topology. Bootstrap support for each tree was estimated based on $100 \mathrm{ML}$ bootstrap replicates with the same options used to generate the ML tree. All sequences were deposited in the NCBI GenBank database (accession numbers MF281799-MF281954).

\section{Results}

Isolation and characterization of PIF cDNAs

We isolated, cloned, and sequenced 156 unique cDNA fragments from the conserved transposase domain of PIFlike TEs in 15 diploid Triticeae samples. As in our previous analysis of genomic PIF sequences, all fragments corresponded to the "DD" portion of the "DDE" transposase motif (Fig. 1b) [45]. PCR amplifications yielded two bands of approximately 360 and $440 \mathrm{bp}$, labeled "S" (short) and "L" (long) in the PIF phylogenies (Figs. 2 and 3), for all samples except Eremopyrum bonaepartis, Triticum monococcum, and Agropyrum cristatum, in which only the longer fragments were detected. The $156 \mathrm{cDNA}$ sequences revealed that the length difference between long and short fragments is explained by the retention of an intron during transcription by 112 PIF transposase fragments, ranging in size from 72 to $88 \mathrm{bp}$. The intron was located six residues upstream of the second D (Fig. 1b), and contained a stop codon in 85 of the sequences. Approximately 30 of the 156 products contained additional deletions and insertions of one or a few bases; thus, some apparently non-functional gene copies are being transcribed. Sequences showed 58.65-100\% nucleotide identity, with the highest level of divergence (41.35\%) found between E. bonaepartis 14L and Psathyrostachys juncea 8L. Identical ORF cDNA fragments were detected in different samples in four cases (marked with rectangles on Fig. 2): Pseudoroegneria libanotica 14L and Taeniatherum caput-medusae1 6L; P. libanotica 4L and Hordeum bogdanii2 17L; T. urartu 5S and T. caputmedusae 2 2S; and T. caput-medusae 2 17S, T. caputmedusae1 5S, and Crithopsis delileana 5S.

Triticeae contain transcriptionally active PIF, but not Pong elements

Our results show that PIF is actively transcribed in all samples. We did not detect any transcriptional activity for the closely related Pong elements, even though a previous study of Pong genomic sequences [46] showed that Pong sequences are, like PIF, widely dispersed within Triticeae, with multiple distinct and genetically diverse transposases coexisting within individual genomes. We do not think the lack of transcripts can be explained as a technical artifact due to poor amplification, because the amplification primers used here are the same ones used to successfully amplify a wide diversity of genomic Pong sequences from the same Triticeae species [46]. The Pong results not only further highlight a difference in transcriptional activity between these otherwise very similar groups of elements, but they also served a practical purpose, as an additional control confirming the absence of genomic DNA contamination in all RNA preparations.

\section{Phylogenetic analysis}

All phylogenetic analyses of the Triticeae PIF-like cDNAs were performed on a region of approximately 360 bp coding sequence; the intron was excluded because of alignment ambiguities. Maximum parsimony topologies (not shown) were in general accordance with the ML topologies, but there was more resolution and support in the ML trees. Given the difficulties of finding an outgroup while providing clarification of phylogenetic relationships between TEs, we used the mid-point rooting method [58] for all of the phylogenetic trees. Although PIF sequences from grass genera outside the wheat tribe are available, they are not appropriate as outgroups for the Triticeae elements because the PIF-like lineages within Triticeae appear to predate the tribe's origin [i.e., some PIF elements from within the Triticeae are more closely related to grass elements from outside of the tribe than they are to other elements from within the tribe [[45]; see also [38, 42]].

\section{Phylogeny of PIF CDNA transcripts in Triticeae}

This data set included all 156 cDNA fragments from all 15 accessions. (A phylogeny of 44 cDNA PIF transcripts with no intron is presented as an Additional file 1). The best topology $(-\ln L=5,169.16730$; Fig. 2$)$ revealed three main groups of PIF cDNAs in Triticeae (I-III in Fig. 2). Psathyrostachys juncea 2L was sister (69\% bootstrap support) to group I (100\% bootstrap), which was the largest and the most complex group, and was further subdivided into two weakly supported subgroups. Group I contained sequences from all samples except $E$. bonaepartis. Within this group, P. libanotica $14 \mathrm{~L}$ was identical to $T$. caput-medusae $16 \mathrm{~L}$ (indicated with rectangles on Fig. 2). Group II (weakly supported) was represented by sequences from all samples except $H$. bogdanii1 and $T$. monococcum. Within this group, three sets of sequences were identical: H. bogdanii2 $17 \mathrm{~L}$ and P. libanotica 4L; $T$. 
caput-medusae $2 \mathrm{~S}$ and T.urartu 5S; and C. delileana 5S, T. caput-medusae $217 \mathrm{~S}$, and T. caput-medusae $15 \mathrm{~S}$ (indicated with rectangles on Fig. 2). Aegilops comosa $9 \mathrm{~S}$ was sister to group II with bootstrap of $64 \%$. Group III (100\% bootstrap support) only included sequences from C. delileana, P. libanotica, and P. juncea. The small size of this group points to a combination of differences in element transcriptional activity, the loss of some lineages through stochastic events and natural selection, and/or random sampling artifacts. Crithopsis delileana and $P$. libanotica exhibited very broad distribution, with cDNA sequences in all of the main evolutionary lineages identified.

Phylogeny of genomic and CDNA PIF transposase fragments This analysis included 156 cDNAs generated for this study along with 240 genomic PIF sequences from a previous phylogenetic study of PIF sequences in Triticeae [45] (Fig. 3). Of the 240 genomic sequences, 113 had frameshifting indels or stop codons, and thus are probably not functional. The best topology $(-\ln L=11,008.92254$; Fig. 3) revealed multiple distinct transposase cDNA fragments grouped with genomic sequences in well-defined and generally well-supported clades (Fig. 3). The wide distribution of cDNA sequences among the genomic sequences showed that they are derived from multiple evolutionary lineages, indicating that distinct transposases have retained transcriptional competence during the evolution of the tribe and have the potential to function simultaneously within a genome (Fig. 3).

Eight cDNAs were identical to genomic PIF fragments (indicated with green rectangles in Fig. 3), suggesting that they originated from identical or nearly identical transposase fragments (although only half of them are paired with genomic copies from the same species). Of these eight transcripts, seven were derived from transposases with no frameshifting indels or stop codons. The eighth, $\mathrm{cH}$. bogdanii2 $7 \mathrm{~L}$, is characterized by four single base pair deletions, resulting in a change of the reading frame, thus demonstrating that transcriptional activity does not necessarily indicate functional activity. Two pairs of genomic transposase sequences were identical (marked with pale blue rectangles on Fig. 3): gThinopyrum bessarabicum 8 and gP.libanotica 14; and gH. bogdanii 15 and gT. urartu 23.

\section{Discussion}

Transcription is the first of several steps required for TE transposition [59]. Autonomous elements (i.e. elements that encode all functional products required for transposition) have the potential to self-activate or regulate the activity of related non-autonomous versions, which are ubiquitous in grass genomes [11]. To ensure the viability of their host, and therefore their own survival, optimized transmission and restricted transpositional activity are the hallmark of many TE families. Once integrated in the host genome, TEs rapidly accumulate small insertions, deletions, and rearrangements that alter their structural integrity and render them inactive [23, 25, 26]. Plant cells have also developed a variety of transcriptional and post-transcriptional regulatory mechanisms to protect their genomes against TE movement, including silencing by increased DNA methylation of promoter regions, histone modifications, or small RNA interference [19, 60-62].

\section{Transcriptional activity of PIF and Pong-like TEs in Triticeae}

Our work on the evolutionary dynamics of PIF and Pong transposase activity in Triticeae had two major goals. The first was to determine whether PIF and Pong are transcriptionally active in Triticeae, and the second was to assess the diversity of transcribed transposase lineages. We found that PIF-like transcripts are present throughout the Triticeae, indicating that they have remained transcriptionally active throughout of the long history of the tribe (13-25 mya; [63]). Phylogenetic analysis of both genomic DNA and cDNA revealed that the detected PIF transcripts belong to distinct clades, and that most, if not all transposase lineages have remained transcriptionally competent. In contrast, we did not detect any transcriptional activity of Pong elements in any sample, in spite of previous work [46] showing that the diversity of Pong elements in Triticeae genomes is comparable to that of PIF elements in the same species, with multiple distinct lineages coexisting within a single genome. Although this work is focused on TE transcriptional activity in mature leaf material only, the lack of Pong activity in the wheat tribe also contrasts with observations from other plant species; Pong elements have undergone recent amplification in Arabidopsis and Brassica [36], and are transcriptionally active in rice [30, 64-66]. One plausible explanation for the lack of Pong-related transcription within Triticeae genomes could be the failure of a related or unrelated TE, transposase gene, or mechanism to activate the transcription machinery of Pong elements in a common ancestor of Triticeae. It is highly unlikely that individual Pong copies have been transcriptionally inactivated separately due to natural selection and/or genetic drift. Based on our previous analyses of Pong elements within Triticeae genomes, their expansion seems to be recent [46], thus it is possible that the element is still active but another mechanism has failed to instigate its transcription and therefore activity.

\section{Phylogeny of PIF cDNA transcripts}

Genome-wide studies of transcriptional activity of 56 maize TE families, the PIF family included, have demonstrated that TE Expressed Sequence Tags (ESTs) 
are located only in a few clades of genomic sequences, indicating that few evolutionary branches of the TEs are transcriptionally active [67]. However, in contrast to these findings, our results revealed that the majority of PIF lineages have retained transcriptional capacity.

The wide distribution of distinct taxa in groups I and II in Fig. 2 suggests that diverse ancestral lineages were vertically transmitted and have remained transcriptionally active during the evolution of the tribe (13-25 mya; [63]). Elements from groups I and II are missing from only a few individuals; this could be attributed either to loss from those genomes or to a sampling artifact. Group III (Fig. 2) is represented in far fewer individuals, which may be due to differential evolutionary success of this transposase lineage due to selection, and/or to stochastic losses. However, the presence of these transcripts in species derived from basal branches of the wheat tribe such as Psathyrostachys [68, 69] indicates this lineage was already present at the beginning of Triticeae radiation, and later lost from some of the descendants.

The presence of identical PIF transposase fragments shared across species boundaries suggests that recent or ongoing occasional horizontal transfer (HT) events have played a significant role in the complex distribution of PIF elements in Triticeae. This was also supported by our previous analysis of PIF dynamics in Triticeae [45], in which we identified two pairs of genomic PIF transposase gene fragments that exhibited extremely high nucleotide sequence identities (marked with pale blue rectangles on Fig. 3). Triticeae genera diverged 13-25 mya [63], and it is highly unlikely that their transposase sequences diverged at the same time as the hosts and maintained such high sequence similarity, even if they are under selective constraints [45]. Here, the identification of identical pairs of cDNA and genomic transposase fragments provides further evidence that HT plays a role in the distribution of PIF elements among genera.

\section{Conclusion}

PIF and Pong-like elements are widely dispersed within the genomes of diploid Triticeae species. However, both TE families display unique features and vary considerably in their transposase transcriptional activity. No Pong-related transcripts were detected, while an abundance of diverse PIF-related transcripts were identified in all samples, indicating wide variations in the activity of closely related transposon families within the same genome. Multiple distinct transcriptionally competent PIF transposase clades were discovered, revealing that transcription of PIF elements in Triticeae is not restricted to few evolutionary lineages.

\section{Additional file}

Additional file 1: 1000 -replicate ML bootstrap analysis of 44 PIF-like cDNA transposase sequences with no intron from Triticeae (only bootstrap values above $50 \%$ are shown). Red rectangles indicate identical sequences from distinct genera. Numbers following taxon names distinguish individuals within species and numbers in parentheses distinguish cloned sequences from within individuals. (EPS $1457 \mathrm{~kb}$ )

\section{Acknowledgements}

We appreciate the very helpful comments on the manuscript provided by three anonymous reviewers.

\section{Funding}

This work was supported by a National Science Foundation Grant (DEB-0426194) to Roberta J. Mason Gamer, and a Provost's Award and an Elmer Hadley Research Award from the University of Illinois at Chicago to Dragomira N. Markova.

\section{Availability of data and materials}

All sequences are deposited in the NCBI GenBank database (accession numbers MF281799-MF281954).

\section{Authors' contributions}

DNM gathered the data and performed the analyses. DNM and RJMG conceived the study and wrote the manuscript. Both authors read and approved the final manuscript.

Ethics approval and consent to participate

Not applicable. No experiments or procedures involving animals were performed in this study.

Consent for publication

Not applicable.

Competing interests

Both authors declare that they have no competing interests.

\section{Publisher's Note}

Springer Nature remains neutral with regard to jurisdictional claims in published maps and institutional affiliations.

Received: 15 January 2017 Accepted: 26 July 2017

Published online: 03 August 2017

\section{References}

1. Löve A. Conspectus of the Triticeae. Feddes Repertorium. 1984;95:425-521.

2. Charles M, Belcram H, Just J, Huneau C, Viollet A, Couloux A, Segurens B, Carter M, Huteau V, Coriton O, et al. Dynamics and differential proliferation of transposable elements during the evolution of the $\mathrm{B}$ and a genomes of wheat. Genetics. 2008;180(2):1071-86.

3. Li W, Zhang P, Fellers JP, Friebe B, Gill BS. Sequence composition, organization, and evolution of the core Triticeae genome. Plant J. 2004; 40(4):500-11.

4. Paux E, Roger D, Badaeva E, Gay G, Bernard M, Sourdille P, Feuillet C. Characterizing the composition and evolution of homoeologous genomes in hexaploid wheat through BAC-end sequencing on chromosome $3 \mathrm{~B}$. Plant J. 2006:48(3):463-74.

5. Wicker T, Taudien S, Houben A, Keller B, Graner A, Platzer M, Stein N. A whole-genome snapshot of 454 sequences exposes the composition of the barley genome and provides evidence for parallel evolution of genome size in wheat and barley. Plant J. 2009:59(5):712-22.

6. Mayer KF, Martis M, Hedley PE, Simkova H, Liu H, Morris JA, Steuernagel B, Taudien S, Roessner S, Gundlach H, et al. Unlocking the barley genome by chromosomal and comparative genomics. Plant Cell. 2011;23(4):1249-63.

7. The International Barley Genome Sequencing Consortium. A physical, genetic and functional sequence assembly of the barley genome. Nature. 2012;491(7426):711-6.

8. Capy P, Bazin C, Hiquet D, Langin T. Dynamics and evolution of transposable elements. TX: Landes Biosciences, Austin; 1998. 
9. Feschotte C, Jiang N, Wessler SR. Plant transposable elements: where genetics meets genomics. Nat Rev Genet. 2002;3(5):329-41.

10. Feschotte C, Wessler SR. Mariner-like transposases are widespread and diverse in flowering plants. Proc Natl Acad Sci U S A. 2002;99(1):280-5

11. Jiang N, Feschotte C, Zhang X, Wessler SR. Using rice to understand the origin and amplification of miniature inverted repeat transposable elements (MITES). Curr Opin Plant Biol. 2004;7(2):115-9

12. Lai J, Li Y, Messing J, Dooner HK. Gene movement by Helitron transposons contributes to the haplotype variability of maize. Proc Natl Acad Sci U S A. 2005; 102(25):9068-73.

13. Lippman Z, Gendrel AV, Black M, Vaughn MW, Dedhia N, WR MC, Lavine K, Mittal V, May B, Kasschau KD, et al. Role of transposable elements in heterochromatin and epigenetic control. Nature. 2004;430(6998):471-6.

14. Ma J, Bennetzen JL. Rapid recent growth and divergence of rice nuclear genomes. Proc Natl Acad Sci U S A. 2004;101(34):12404-10.

15. Morgante M, Brunner S, Pea G, Fengler K, Zuccolo A, Rafalski A. Gene duplication and exon shuffling by helitron-like transposons generate intraspecies diversity in maize. Nat Genet. 2005;37(9):997-1002.

16. Wang W, Zheng H, Fan C, Li J, Shi J, Cai Z, Zhang G, Liu D, Zhang J, Vang S, et al. High rate of chimeric gene origination by retroposition in plant genomes. Plant Cell. 2006:18(8):1791-802.

17. Bennetzen JL. Transposable element contributions to plant gene and genome evolution. Plant Mol Biol. 2000;42(1):251-69.

18. Biemont C, Vieira C. Genetics: junk DNA as an evolutionary force. Nature. 2006:443(7111):521-4.

19. Lippman Z, Martienssen R. The role of RNA interference in heterochromatic silencing. Nature. 2004;431(7006):364-70.

20. Casacuberta E, Gonzalez J. The impact of transposable elements in environmental adaptation. Mol Ecol. 2013;22(6):1503-17.

21. Hayward A, Ghazal A, Andersson G, Andersson L, Jern P. ZBED evolution: repeated utilization of DNA transposons as regulators of diverse host functions. PLoS One. 2013:8(3):e59940.

22. Majumdar S, Singh A, Rio DC. The human THAP9 gene encodes an active Pelement DNA transposase. Science. 2013;339(6118):446-8.

23. Lampe DJ, Witherspoon DJ, Soto-Adames FN, Robertson HM. Recent horizontal transfer of mellifera subfamily mariner transposons into insect lineages representing four different orders shows that selection acts only during horizontal transfer. Mol Biol Evol. 2003;20(4):554-62.

24. Silva JC, Loreto EL, Clark JB. Factors that affect the horizontal transfer of transposable elements. Curr Issues Mol Biol. 2004:6(1):57-71.

25. Witherspoon DJ. Selective constraints on P-element evolution. Mol Biol Evol. 1999;16(4):472-8

26. Silva JC, Kidwell MG. Evolution of P elements in natural populations of Drosophila Willistoni and D. Sturtevanti. Genetics. 2004;168(3):1323-35.

27. Zilberman $D$, Henikoff $S$. Silencing of transposons in plant genomes: kick them when they're down. Genome Biol. 2004;5(12):249.

28. Casola C, Lawing AM, Betran E, Feschotte C. PIF-like transposons are common in drosophila and have been repeatedly domesticated to generate new host genes. Mol Biol Evol. 2007;24(8):1872-88.

29. de Araujo PG, Rossi M, de Jesus EM, Saccaro NL Jr, Kajihara D, Massa R, de Felix $J M$, Drummond RD, Falco MC, Chabregas SM, et al. Transcriptionally active transposable elements in recent hybrid sugarcane. Plant J. 2005;44(5):707-17.

30. Jiang N, Bao Z, Zhang X, Hirochika H, Eddy SR, SR MC, Wessler SR. An active DNA transposon family in rice. Nature. 2003;421(6919):163-7.

31. Lopes FR, Carazzolle MF, Pereira GA, Colombo CA, Carareto CM. Transposable elements in Coffea (Gentianales: Rubiacea) transcripts and their role in the origin of protein diversity in flowering plants. Mol Gen Genomics. 2008;279(4):385-401.

32. Ohtsu K, Smith MB, Emrich SJ, Borsuk LA, Zhou R, Chen T, Zhang X, Timmermans MC, Beck J, Buckner B, et al. Global gene expression analysis of the shoot apical meristem of maize (Zea Mays L.). Plant J. 2007;52(3):391-404.

33. Vicient $\mathrm{CM}$, Jaaskelainen MJ, Kalendar R, Schulman AH. Active retrotransposons are a common feature of grass genomes. Plant Physiol. 2001;125(3):1283-92

34. Walker EL, Eggleston WB, Demopulos D, Kermicle J, Dellaporta SL. Insertions of a novel class of transposable elements with a strong target site preference at the $r$ locus of maize. Genetics. 1997;146(2):681-93.

35. Grzebelus D, Lasota S, Gambin T, Kucherov G, Gambin A. Diversity and structure of PIF/harbinger-like elements in the genome of Medicago Truncatula. BMC Genomics. 2007;8:409.
36. Zhang X, Wessler SR. Genome-wide comparative analysis of the transposable elements in the related species Arabidopsis Thaliana and Brassica Oleracea. Proc Natl Acad Sci U S A. 2004;101(15):5589-94.

37. Zhong H, Zhou M, Xu C, Tang D-Q. Diversity and evolution of pong-like elements in Bambusoideae subfamily. Bio Syst Ecol. 2010;38(4):750-8.

38. Zhou M-B, Lu J-J, Zhong H, Liu X-M, Tang D-Q. Distribution and diversity of PIF-like transposable elements in the Bambusoideae subfamily. Plant Sci. 2010;179(3):257-66.

39. Ding Z, Gillespie LL, Mercer FC, Paterno GD. The SANT domain of human MI-ER1 interacts with Sp1 to interfere with GC box recognition and repress transcription from its own promoter. J Biol Chem. 2004;279(27):28009-16.

40. Mo X, Kowenz-Leutz E, Laumonnier Y, Xu H, Leutz A. Histone H3 tail positioning and acetylation by the c-Myb but not the v-Myb DNA-binding SANT domain. Genes Dev. 2005;19(20):2447-57.

41. Sterner DE, Wang X, Bloom MH, Simon GM, Berger SL. The SANT domain of Ada2 is required for normal acetylation of histones by the yeast SAGA complex. J Biol Chem. 2002;277(10):8178-86.

42. Zhang X, Jiang N, Feschotte C, Wessler SR. PIF- and pong-like transposable elements: distribution, evolution and relationship with tourist-like miniature inverted-repeat transposable elements. Genetics. 2004;166(2):971-86.

43. Rezsohazy R, Hallet B, Delcour J, Mahillon J. The IS4 family of insertion sequences: evidence for a conserved transposase motif. Mol Microbiol. 1993;9(6):1283-95

44. Yuan YW, Wessler SR. The catalytic domain of all eukaryotic cut-and-paste transposase superfamilies. Proc Natl Acad Sci U S A. 2011;108(19):7884-9.

45. Markova DN, Mason-Gamer RJ. The role of vertical and horizontal transfer in the evolutionary dynamics of PIF-like transposable elements in Triticeae. PLoS One. 2015;10(9):e0137648.

46. Markova DN, Mason-Gamer RJ. Diversity, abundance, and evolutionary dynamics of pong-like transposable elements in Triticeae. Mol Phylogenet Evol. 2015;93:318-30

47. Kapitonov W, Jurka J. Molecular paleontology of transposable elements in the Drosophila Melanogaster genome. Proc Natl Acad Sci U S A. 2003; 100(11):6569-74

48. Doyle JJ. A rapid DNA isolation procedure for small quantities of fresh leaf tissue. Phytochem bull. 1987;19:11-5.

49. Wagner A, Blackstone N, Cartwright P, Dick M, Misof B, Snow P, Wagner GP, Bartels J, Murtha M, Pendleton J. Surveys of gene families using polymerase chain reaction: PCR selection and PCR drift. Syst Biol. 1994; 43:250-61.

50. Thompson JD, Higgins DG, Gibson TJ. CLUSTAL W: improving the sensitivity of progressive multiple sequence alignment through sequence weighting, position-specific gap penalties and weight matrix choice. Nucleic Acids Res. 1994:22(22):4673-80.

51. Swofford DL. Phylogenetic analysis using parsimony (*and other methods). Sunderland, Massachussets: Sinauer Associates; 2003.

52. Felsenstein J. Confidence limits on phylogenies: an approach using the bootstrap. Evolution. 1985;39(4):783-91.

53. Posada D. jModelTest: phylogenetic model averaging. Mol Biol Evol. 2008; 25(7):1253-6.

54. Posada D. Selection of models of DNA evolution with jModelTest. Methods Mol Biol. 2009:537:93-112.

55. Posada D, Crandall KA. MODELTEST: testing the model of DNA substitution. Bioinformatics. 1998:14(9):817-8.

56. Posada D, Buckley TR. Model selection and model averaging in phylogenetics: advantages of akaike information criterion and bayesian approaches over likelihood ratio tests. Syst Biol. 2004;53(5):793-808.

57. Zwickl DJ. Genetic algorithm approaches for the phylogenetic analysis of large biological sequence datasets under the maximum likelihood criterion: Ph.D. dissertation, University of Texas, Austin, Texas, USA. 2006.

58. Farris JS. Estimating Phylogenetic trees from distance matrices. Am Nat. 1972;106(951):645-68.

59. Fedoroff N. Transposons and genome evolution in plants. Proc National Academy Sci. 2000;97(13):7002-7.

60. Kasschau KD, Fahlgren N, Chapman EJ, Sullivan CM, Cumbie JS, Givan SA, Carrington JC. Genome-wide profiling and analysis of Arabidopsis siRNAs. PLoS Biol. 2007:5(3):e57.

61. Martienssen R, Lippman Z, May B, Ronemus M, Vaughn M. Transposons, tandem repeats, and the silencing of imprinted genes. Cold Spring Harb Symp Quant Biol. 2004;69:371-9. 
62. Tanurdzic M, Vaughn MW, Jiang H, Lee TJ, Slotkin RK, Sosinski B, Thompson WF, Doerge RW, Martienssen RA. Epigenomic consequences of immortalized plant cell suspension culture. PLoS Biol. 2008;6(12):2880-95.

63. Gaut BS. Evolutionary dynamics of grass genomes. New Phytol. 2002;154(1): $15-28$.

64. Jiao Y, Deng XW. A genome-wide transcriptional activity survey of rice transposable element-related genes. Genome Biol. 2007;8(2):R28.

65. Nakazaki T, Okumoto Y, Horibata A, Yamahira S, Teraishi M, Nishida H, Inoue $\mathrm{H}$, Tanisaka T. Mobilization of a transposon in the rice genome. Nature. 2003;421(6919):170-2.

66. Shan X, Liu Z, Dong Z, Wang Y, Chen Y, Lin X, Long L, Han F, Dong Y, Liu B. Mobilization of the active MITE transposons $\mathrm{mPing}$ and pong in rice by introgression from wild rice (Zizania Latifolia Griseb.). Mol Biol Evol. 2005; 22(4):976-90.

67. Vicient CM. Transcriptional activity of transposable elements in maize. BMC Genomics. 2010;11:601.

68. Escobar JS, Scornavacca C, Cenci A, Guilhaumon C, Santoni S, Douzery EJ, Ranwez V, Glemin S, David J. Multigenic phylogeny and analysis of tree incongruences in Triticeae (Poaceae). BMC Evol Biol. 2011;11:181.

69. Mason-Gamer RJ, Orme NL, Anderson CM. Phylogenetic analysis of north American Elymus and the monogenomic Triticeae (Poaceae) using three chloroplast DNA data sets. Genome. 2002:45(6):991-1002.

Submit your next manuscript to BioMed Central and we will help you at every step:

- We accept pre-submission inquiries

- Our selector tool helps you to find the most relevant journal

- We provide round the clock customer support

- Convenient online submission

- Thorough peer review

- Inclusion in PubMed and all major indexing services

- Maximum visibility for your research

Submit your manuscript at www.biomedcentral.com/submit
Biomed Central 